\title{
New Central American and Mexican Enaphalodes Haldeman, 1847 (Coleoptera: Cerambycidae) with taxonomic notes and a key to species
}

\author{
Steven W. Lingafelter ${ }^{1} \&$ Antonio Santos-Silva² \\ 1 University of Arizona (UA), Department of Entomology, Insect Collection (UAIC). Tucson, Arizona, U.S.A. E-mail: elaphidion@gmail.com \\ ${ }^{2}$ Universidade de São Paulo (USP), Museu de Zoologia (MZUSP). São Paulo, SP, Brasil. E-mail: toncriss@uol.com.br
}

\begin{abstract}
A review of Enaphalodes Haldeman, 1847 is presented. Descriptions of four new species of Enaphalodes are included: E. antonkozlovi, sp. nov. from Costa Rica, E. bingkirki, sp. nov. from Nicaragua, E. monzoni, sp. nov. from Guatemala, and E. cunninghami, sp. nov. from Mexico. Enaphalodes senex (Bates, 1884) is revalidated and it is newly recorded from Nicaragua and Guatemala. A key to the 15 currently recognized species of Enaphalodes is included.
\end{abstract}

Key-Words. Cerambycinae; Elaphidiini; Key; Long horned beetle; Taxonomy.

\section{INTRODUCTION}

The genus Enaphalodes Haldeman (1847) was originally listed in Dejean's (1836) catalogue, but it is an unavailable name since it had no description or included species and therefore did not meet Article 12 of the International Code of Zoological Nomenclature (ICZN, 1999). This was further corroborated by Bousquet \& Bouchard (2013) in their analysis of available names from this publication. Haldeman (1847) made the genus name available by describing a species, E. simplicicollis, within it. This species is currently a synonym of E. hispicornis (Linnaeus, 1767).

Linsley (1963), in his monograph of the Cerambycidae of North America, designated the type species, E. pulverulentus De Geer, 1775. That species is currently a synonym of E. atomarius (Drury, 1773). In that work, Linsley listed eight species for North America, but the work did not treat the single Central American species known at that time, E. coronatus (White, 1853). Lingafelter \& Chemsak (2002) provided a review of the genus Enaphalodes, describing one new species from Florida, E. archboldi Lingafelter \& Chemsak, and making two synonymies: Hypermallus decipiens Bates, 1884, as a synonym of Enaphalodes atomarius and Romaleum cylindricum Knull, 1927, as a synonym of E. cortiphagus (Craighead, 1923). As of that work, nine species of Enaphalodes were known, mostly distributed in the United States and Mexico, with E. coronatus known only from Central America.

Martins (2005) in his South American Cerambycidae monograph, described the only known South American species of Enaphalodes, E. boyacanus. Thus, as of that work, 10 species of
Enaphalodes were known, with only two species known from Central and South America.

In this work, we describe four new species of Enaphalodes: E. antonkozlovi from Costa Rica, E. bingkirki from Nicaragua, E. monzoni from Guatemala, and E. cunninghami from Mexico. We revalidate $E$. senex (Bates, 1884) and newly record it from two countries, Nicaragua and Guatemala. We provide a key to the 15 species of Enaphalodes that are currently known.

\section{MATERIALS AND METHODS}

Photographs were taken and stacked with two systems: (1) Canon EOS Rebel T3i DSLR camera, Canon MP-E 65 mm f/2.8 1-5X macro lens, controlled by Zerene Stacker AutoMontage software; (2) Nikon Digital Sight DS-F12 camera mounted on a Nikon SMZ18 stereo microscope with 0.5X SHR Plan Apo lens, controlled by Helicon Focus 6.5.3 rendering software. Measurements were taken in "mm" using a Hensoldt/Wetzlar - Mess 10 ocular micrometer in the Leica MZ6 stereo microscope, and through calibration with the Nikon SMZ18 stereo microscope. The collection acronyms used in this study are as follows:

ACMT: American Coleoptera Museum (James E. Wappes), San Antonio, Texas, U.S.A.

CNIN: Coleccion Nacional de Insectos, Instituto de Biologia (UNAM), Mexico City, Mexico

DJHC: Daniel J. Heffern Collection, Houston, Texas, U.S.A.

EMEC: Essig Museum of Entomology, Berkeley, California, U.S.A. 
FSCA: Florida State Collection of Arthropods, Gainesville, Florida, U.S.A.

FWSC: Frederick W. Skillman Jr., Collection, Pearce, Arizona, U.S.A.

BMNH: The Natural History Museum, London, United Kingdom

MZSP: Museu de Zoologia, Universidade de São Paulo, São Paulo, Brazil

USNM: National Museum of Natural History, Washington D.C., U.S.A.

\section{RESULTS AND DISCUSSION}

\section{Enaphalodes Haldeman, 1847}

Enaphalodes Haldeman, 1847: 151.

Type-species: Cerambyx pulverulentus De Geer, 1775 (subsequent designation, Linsley, 1963: 63) [= Cerambyx atomarius Drury, 1773].

A full nomenclatural history of Enaphalodes was presented in Monné (2005: 212). Lingafelter \& Chemsak (2002) presented a full diagnosis of Enaphalodes with comparison to related genera of Elaphidiini and it is thus unnecessary to repeat that in this work. The new species described below generally conform to the genus in having the metepisternum very broad anteriorly, the prosternal process broadly expanded apically and nearly closing the procoxal cavities posteriorly (although E. antonkozlovi, sp. nov. is an exception, having an acutely declivous and weakly expanded prosternal process that is similar to many species of Elaphidion Audinet-Serville, 1834), the mesosternum lacking lateral processes into the mesocoxae, and antennomere three almost two-thirds the length of the pronotum. Most species have the elytra with irregular patches of pubescence and glabrous regions (although E. seminitidus Horn, 1885 is an exception in that it lacks appressed pubescence and E. hispicornis (Linnaeus, 1767) and E. archboldi Lingafelter \& Chemsak, 2002 have uniformly-distributed pubescence). Most species of Enaphalodes have the femoral apices unspined, although E. boyacanus Martins, 2005 and E. antonkozlovi, sp. nov. are exceptions with strongly spined meso- and metafemoral apices.

\section{Enaphalodes antonkozlovi, sp. nov.} (Figs. 1-5)

Diagnosis: Enaphalodes antonkozlovi differs from most other species of the genus by having strongly spined meso- and metafemoral apices and an acutely declivous prosternal process that is weakly expanded apically (Fig. 5). Only E. boyacanus has similarly spined femora. All other Enaphalodes species have the femoral apices rounded and weakly projecting. Enaphalodes antonkozlovi further differs from other species by the mesosternal process having a transverse central tubercle (Fig. 5). In the other species the mesosternal process has a small tubercle placed on each side of the base or is unarmed or nearly so. It also differs from E. coronatus (White, 1853) by the dense, pale yellow-ochre pubescence (Fig. 1), the mesosternal process being wider (Fig. 5), and the apices of the meso- and metafemora distinctly spiniform (Fig. 4). In E. coronatus, the dense pubescence is white (Fig. 6), the mesosternal process is narrower (Fig. 8), and the apices of the meso- and metafemora have, at most, a triangular lobe (Fig. 7). It can be separated from E. taeniatus (LeConte, 1854) by the same features as E. coronatus, by the relatively slender body, and the antennae that distinctly surpass the elytral apex in females. In E. taeniatus, the body is wider and the antennae of females do not surpass the elytral apex (Fig. 51).

Description: Holotype female: Integument mostly black; parts of mouthparts yellowish-brown; antennomeres $\mathrm{VI}-\mathrm{XI}$ grade from dark brown to brown; femora mostly dark brown except black base and apex; distal transverse area of abdominal ventrites II-III dark brown; distal transverse area of abdominal ventrite IV yellowish-brown.

Head: Frons centrally tumid, with deep fovea on each side close to clypeus; with pale yellow-ochre pubescence obscuring integument except glabrous, central triangular area from clypeus to area between antennal tubercles; with some long, erect yellow setae laterally. Area between antennal tubercles with pubescence as on frons. Remaining surface of vertex with pubescence as on frons except Y-shaped nearly glabrous central area from prothoracic margin to area between upper eye lobes (with short, sparse setae on area between upper eye lobes); with some long, erect yellow setae close to eyes. Area behind upper eye lobes with shallow sulcus close to eye, widened toward lower eye lobes, finely, confluently punctate inside distal area of sulcus, finely, moderately, sparsely punctate on remaining surface; with fringe of short yellowish-white pubescence inside sulcus, nearly glabrous on remaining surface. Area behind lower eye lobes nearly smooth close to upper eye lobes, transversely striate-punctate toward ventral side; with fringe of yellowish-white pubescence close to eye, from midlength toward ventral side, glabrous on remaining surface. Antennal tubercles flat; pubescence as on frons on inner side except glabrous area close to apex; area closer to lower eye lobes with short, sparse yellowish-white setae. Genae finely, sparsely punctate (punctures slightly coarser toward ventral side); with short, decumbent, sparse yellowish-white setae. Postclypeus with pubescence as on frons on lateral areas close to frons, with short, sparse yellowish-white setae on remaining surface interspersed with long, erect yellowish-white setae. Labrum coplanar with anteclypeus on basal half, slightly inclined laterally on distal half, nearly vertical centrally; finely, sparsely punctate on basal half; with short and long, sparse yellowish-white setae on basal half, with long, abundant golden setae directed forward on distal half. Gula smooth, glabrous. Submentum transversely striate-punctate; with short, decumbent grayish-white setae, not obscuring integument, interspersed with 

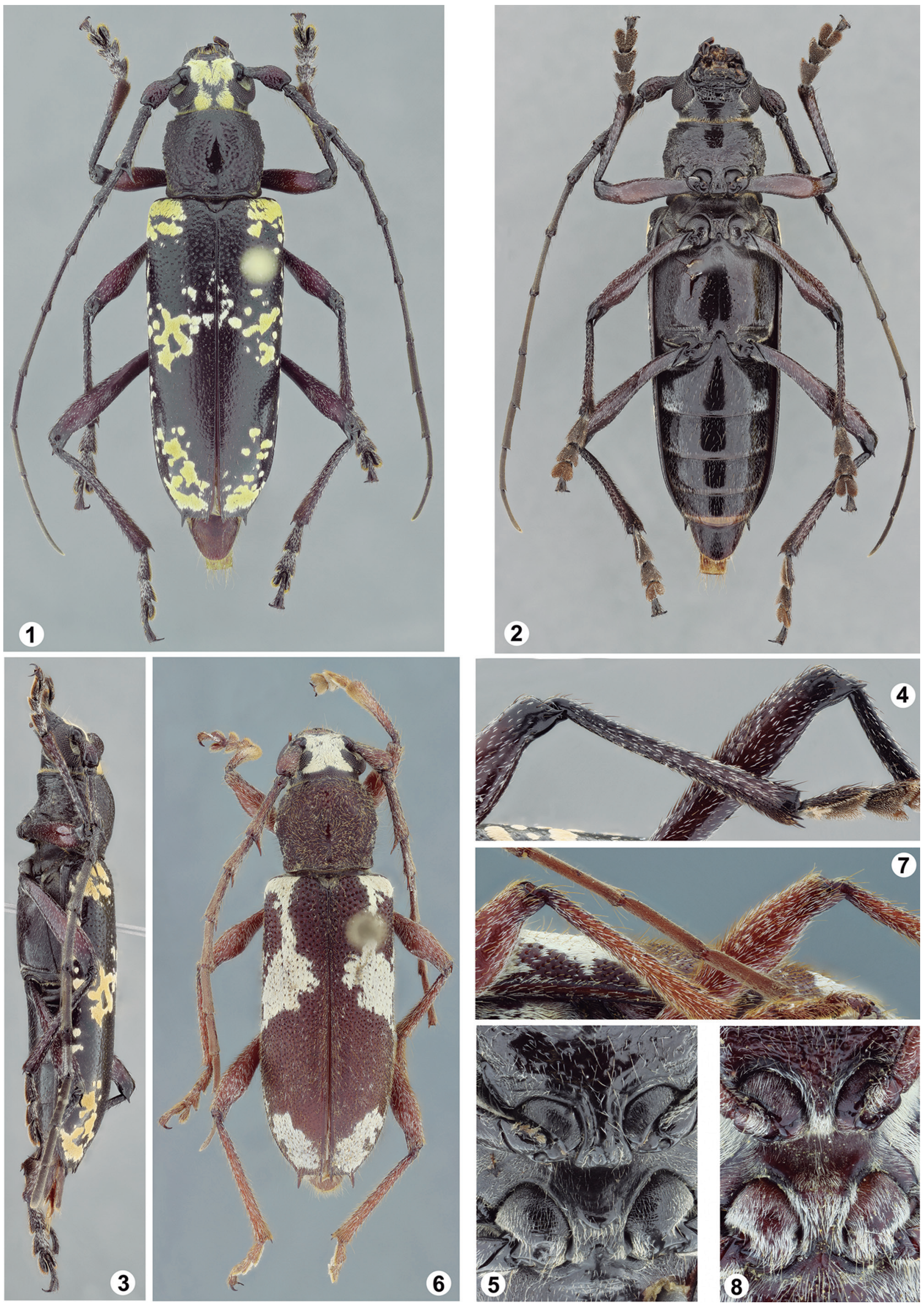

Figures 1-8. (1-5): Enaphalodes antonkozlovi, sp. nov., holotype female: (1) Dorsal habitus; (2) Ventral habitus; (3) Lateral habitus; (4) Apices of meso- and metafemora; (5) Pro- and mesosternal processes. (6-8): Enaphalodes coronatus, female: (6) Dorsal habitus; (7) Apices of meso- and metafemora; (8) Pro- and mesosternal processes. 
long, erect, setae of same color. Distance between upper eye lobes 0.60 times length of scape; in frontal view, distance between lower eye lobes 0.95 times length of scape. Antennae 1.7 times elytral length, reaching elytral apex at base of antennomere X. Scape piriform, dorsoventrally flattened at about basal third, notably widened on distal $2 / 3$; dorsal surface slightly depressed on basal third; moderately coarsely, densely punctate; with short, decumbent, sparse yellowish-white setae interspersed with long, erect yellowish setae on ventral side of distal $2 / 3$. Antennomeres III-VII dorsoventrally flattened except on distal area (gradually less evidently toward VII); inner apex of antennomere III with acute spine, longer than distal width of antennomere; inner apex of antennomere IV with acute spine, slightly shorter than distal width of antennomere; antennomeres $\mathrm{V}-\mathrm{X}$ with short spine at inner and outer apices, shorter at outer apex of V-VII, slightly conspicuous at outer apex of $\mathrm{X}$; antennomeres with yellowish-white setae dorsally, gradually shorter and denser toward distal antennomeres; antennomeres III-VI with long, erect yellowish setae ventrally, gradually sparser toward VI. Antennal formula (ratio) based on length of antennomere III (excluding spine): scape $=0.89 ;$ pedicel $=0.16 ; \mathrm{IV}=0.74 ; \mathrm{V}=1.01 ; \mathrm{VI}=1.05$; $\mathrm{VII}=1.08 ; \mathrm{VIII}=0.92 ; \mathrm{IX}=0.84 ; \mathrm{X}=0.73 ; \mathrm{XI}=0.90$.

Thorax: Prothorax slightly wider than long, with distinct constriction near apex; sides slightly rounded. Pronotum with five, slightly elevated gibbosities: one elongate, oblique, placed on each side of basal half; one subovate, placed on each side of distal half; one longitudinal, placed centrally from near base to near apex (narrowed on distal third). Pronotal surface coarsely, shallowly, confluently punctate except on smooth central gibbosity, and central area close to basal and distal margins; with short, decumbent, sparse yellowish-white setae, slightly denser laterally (primarily near basal margin), except on glabrous central gibbosity; with long, erect yellowish-white setae laterally and near distal margin. Sides of prothorax with sculpture as on sides of pronotum; with short, yellowish-white pubescence not obscuring integument, interspersed with long, erect, yellowish-white setae. Prosternum coarsely, sparsely punctate on basal $2 / 3$ (punctures shallower centrally), transversely striate on distal third; with short, decumbent, sparse whitish setae, denser laterally on basal $2 / 3$, sparser on distal third, interspersed with long, erect, whitish setae, primarily on basal $2 / 3$; central area of prosternal process with about half of width of procoxal cavity. Ventral side of mesothorax with yellowish-white pubescence (more whitish depending on angle of light), primarily on sides of mesosternum, mesepisternum and mesepimeron; mesosternal process with distinct transverse central tubercle, and anterior margin gradually inclined toward mesosternum. Metepisternum with whitish pubescence partially obscuring integument (more yellowish depending on angle of light). Metasternum finely, sparsely punctate, interspersed with coarser punctures toward central sulcus; laterally with whitish pubescence interspersed with short, suberect yellowish setae, centrally with short, suberect, sparse yellowish setae, gradually glabrous toward central sulcus. Scutellum laterally with yellow pubescence not obscuring integument, glabrous centrally.

Elytra: Coarsely, densely punctate on basal third, gradually finer, sparser toward apex; with three groups of important maculae of dense pale yellow-ochre pubescence nearly all partially bordered with white pubescence (entirely white centrally toward suture) (Fig. 1); remaining surface with minute, sparse, yellow-ochre setae; with long, erect, sparse yellowish setae on distal quarter; apex truncate, bispinose (outer spine longer).

Legs: Femora with whitish pubescence not obscuring integument, interspersed with short, erect dark setae on meso- and metafemora; inner apex of profemora with rounded lobe and outer apex with triangular lobe; inner and outer apex of meso- and metafemora with spine (mesofemora with inner spine longer than outer, with similar length at metafemora).

Abdomen: Ventrites with white pubescence, sparser centrally, and distinctly denser laterally on ventrite I; with long, erect, sparse yellowish setae; apex of ventrite $\checkmark$ rounded.

Dimensions in mm: Total length, 24.75; prothorax: central length, 4.15; distal width, 3.65; basal width, 4.60; widest width, 4.85; humeral width, 6.20; elytral length, 15.60 .

Type material: Holotype female from COSTA RICA, Cartago: $09^{\circ} 46^{\prime} 51.67^{\prime \prime} \mathrm{N} / 83^{\circ} 46^{\prime} 9.87^{\prime \prime} \mathrm{W}, \quad 19 . \mathrm{VI} .2015$, A. Kozlov \& R. Gortovannyi, col. (MZSP).

Etymology: The new species is named for Anton Olegovich Kozlov, who sent and donated the holotype to MZSP collection

\section{Enaphalodes bingkirki, sp. nov. (Figs. 9-16, 24)}

Diagnosis: Enaphalodes bingkirki is generally very similar to E. niveitectus (Schaeffer, 1905) and E. monzoni, sp. nov. It differs from $E$. niveitectus by having very dense erect, elytral setae (most easily seen from lateral view, Fig. 11), shorter antennae (extending to about apical sixth of elytra in females-males unknown), and the antennal tubercles only slightly elevated, flat, and rounded at their apices (Figs. 9, 12). Females (and presumably males) of $E$. niveitectus have relatively longer antennae that surpass the elytral apex and the antennal tubercles are more elevated with acute apices. Other differences between E. bingkirki and E. niveitectus include more fragmented dense, appressed elytral pubescence in E. bingkirki with large sections bare of dense setae, denser and longer pubescence on the mesosternal process that obscures the apex, and a very narrow, elongate, median pronotal callus. In E. niveitectus, the dense, appressed elytral pubescence covers much more of the surface with only small, 

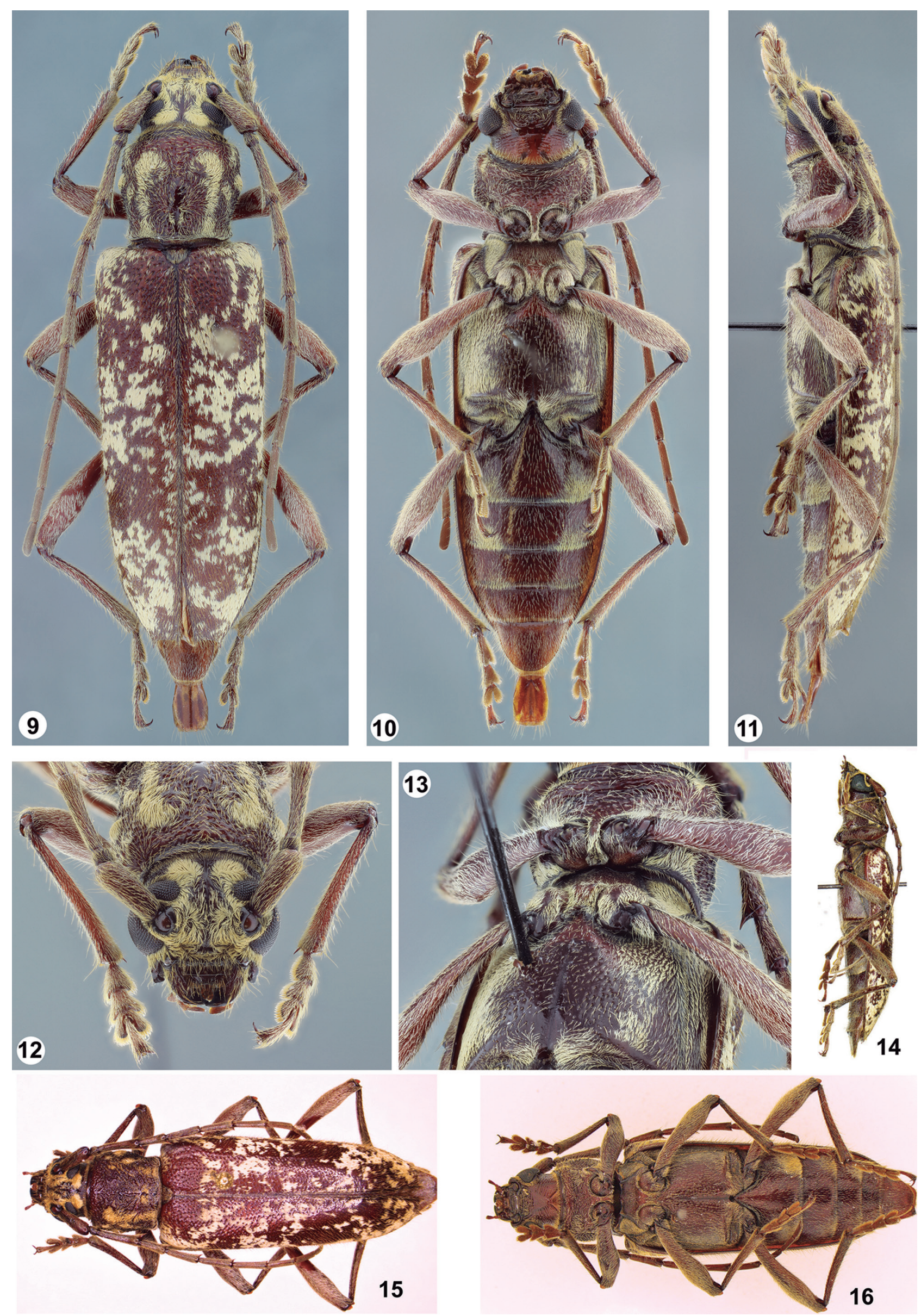

Figures 9-16. Enaphalodes bingkirki, sp. nov.: (9-13): Holotype female: (9) Dorsal habitus; (10) Ventral habitus; (11) Lateral habitus; (12) Head, frontal view; (13) Pro- and mesosternal process. (14-16): Paratype female: (14) Lateral habitus; (15) Dorsal habitus; (16) Ventral habitus. 
scattered areas of the elytra bare of dense setae. Likewise, the setae on the mesosternal process of E. niveitectus are shorter and do not conceal the apex and the median pronotal callus is shorter and broader. Enaphalodes bingkirki is distinguished from E. monzoni, sp. nov. by the antennae reaching the distal sixth of the elytra, the prothorax being narrower and having a distinct lateral tubercle just anterior of the midpoint (Fig. 9), and having the pro- and mesosternal processes narrower (Fig. 24).

Description: Holotype female: Integument mostly dark reddish-brown; ventral side of head mostly light reddish-brown.

Head: Frons slightly elevated above lateral impression near clypeus; with yellow-ochraceous pubescence obscuring most of integument except glabrous, central diamond shaped area on vertex between antennal tubercles and upper eye lobes; with scattered, sparse, long, erect setae along posterior and anterior margins of eyes. Pubescence densest in patches extending from posterodorsal eye margins to occiput, around antennal tubercles and anterior eye margins. Eyes slightly projecting, particularly on posteroventral regions that is elevated by a smooth, glabrous margin. Area behind upper eye lobes, within dense pubescent patch, with shallow sulcus close to eye on either side. Punctation shallow, irregularly sized, mostly obscured by pubescence except directly posterior to eye margin at sides of head and ventrally, where punctures are exposed and the integument is somewhat striate and rugose. Antennal tubercles nearly flat, imperceptibly elevated, with rounded apices; mostly glabrous and shiny around margins. Genae finely, sparsely punctate, with fringe of ochraceous setae at base, anteriorly directed toward glabrous anterior margins. Postclypeus with pubescence as on frons on lateral areas close to frons, with short, sparse yellow-ochraceous setae on remaining surface. Labrum coplanar with anteclypeus on basal half, slightly inclined laterally on distal half, more so centrally; impunctate except along anterior margin which is lined with long, yellow-ochraceous setae directed forward. Gula smooth, glabrous, with rugose, crenulate sculpturing along margins, extending laterally. Submentum striate-punctate; with short, decumbent yellowish setae, not obscuring integument, interspersed with long, erect, setae of same color. Distance between upper eye lobes 0.65 times length of scape; in frontal view, distance between lower eye lobes equal to length of scape. Antennae 1.2 times elytral length, reaching at about distal seventh of elytra. Scape cylindrical, apex slightly broader than base; moderately punctate, more coarsely so at base, becoming finer and denser toward apex; with moderate, appressed yellow-ochraceous pubescence throughout, not obscuring surface; scattered, long, erect yellowish setae present on ventral side of distal $2 / 3$. Antennomeres III-VII dorsoventrally flattened except on distal area (gradually less evidently toward VII); inner apex of antennomere III and IV with acute spine, longer than distal width of antennomeres; inner apex of antennomere $\mathrm{V}$ with acute spine, slightly shorter than distal width of antennomere; antennomeres VI-VII with very short spine at inner apex and dentiform at outer apex; antennomeres with yellowish-ochraceous setae dorsally, gradually shorter and denser toward distal antennomeres; antennomeres III-VI with long, erect yellow-ochraceous setae ventrally, gradually sparser toward VI. Antennal formula (ratio) based on length of antennomere III (excluding spine): scape $=0.92$; pedicel $=0.25$; $\mathrm{IV}=0.66 ; \mathrm{V}=0.86 ; \mathrm{VI}=0.86 ; \mathrm{VII}=0.86 ; \mathrm{VIII}=0.75 ; \mathrm{IX}=0.75$; $\mathrm{X}=0.60 ; \mathrm{XI}=0.66$.

Thorax: Prothorax slightly wider than long; widest at anterior half, with slight constriction atapical margin and before base; sides with a distinct tubercle just anterior of middle. Pronotum with one elongate, poorly defined, mostly smooth and shiny median callus; a less distinct broad callus, micropunctate and mostly covered with dense, ochraceous pubescence on either side of median callus anteriorly. Pronotal surface coarsely, shallowly, confluently punctate except on smooth central callus, and on micropunctate anterolateral calli. Short, decumbent, sparse yellow-ochraceous setae sparsely distributed at center of disk, in dense patches on sides of disk and along posterior fourth. Sides of prothorax with sculpture as on sides of pronotum; with short, yellowish-ochraceous pubescence not obscuring integument except for median patch, interspersed with long, erect, yellowish-ochraceous setae. Prosternum coarsely, sparsely punctate on basal $2 / 3$ (punctures shallower centrally), transversely striate-rugose on distal third; with short, decumbent, sparse yellowish setae, denser laterally on basal $2 / 3$, sparser on distal third; width of central area of prosternal process about $1 / 3$ of width of procoxal cavity; less than half width of mesosternal process. Ventral side of mesothorax with yellowish-ochraceous pubescence, densest on sides of mesosternum, mesepisternum and mesepimeron; mesosternal process without central tubercle, and anterior margin gradually impressed toward mesosternum. Metepisternum with yellow-ochraceous pubescence partially obscuring integument. Metasternum moderately finely, sparsely punctate, interspersed with coarser punctures toward central sulcus; laterally with whitish pubescence interspersed with short, suberect yellowish setae, centrally with short, suberect, sparse yellowish setae, gradually glabrous toward central sulcus. Scutellum with ochraceous pubescence partially obscuring integument, less dense laterally.

Elytra: Punctures moderately deep and coarse on basal third, gradually shallower and smaller posteriorly; nearly indistinct near apex; each puncture bearing a long, erect seta, very dense as viewed laterally; scattered small and interconnected patches of dense, appressed, yellow-ochraceous pubescence throughout, but with less exposed integument at apex and more at base. Apex truncate and equally bispinose.

Legs: Femora with moderately dense, pale yellowish pubescence partially obscuring integument; inner and outer apices of femora with rounded lobes, lacking spines. 
Abdomen: Ventrites with short yellow-ochraceous pubescence, sparser centrally, and distinctly denser laterally on ventrites I-III; apex of ventrite $\mathrm{V}$ rounded.

Variation: Head, scutellum integument light to dark brown; apex of mandibles piceous; distance between upper eye lobes 0.65-0.75 times length of scape; in frontal view, distance between lower eye lobes 1.0-1.2 times length of scape; antennae 1.1-1.2 times elytral length; antennal formula (ratio) of paratype based on length of antennomere III (excluding spine): scape $=0.89$; pedicel $=0.16 ; \mathrm{IV}=0.74 ; \mathrm{V}=1.01 ; \mathrm{VI}=1.05 ; \mathrm{VII}=1.08$; $\mathrm{VIII}=0.92 ; \mathrm{IX}=0.84 ; \mathrm{X}=0.73 ; \mathrm{XI}=0.90$.

Dimensions in $\mathrm{mm}$ (holotype female/paratype female: Total length, 39.9/24.3; prothorax: central length, 5.1/4.7; distal width, 4.5/5.0; basal width, 5.0/5.0; widest width, 6.0/6.4; humeral width, 7.9/7.4; elytral length, 19.6/16.9.

Type material: Holotype female, from NICARAGUA, Nueva Segovia: Cerro Jesus $\left(13^{\circ} 58^{\prime} \mathrm{N}, 86^{\circ} 10^{\prime} \mathrm{W}, 1,300 \mathrm{~m}\right.$, at MV/UV lights), 07-13.VI.2015, Wappes \& Morris col. (FSCA). Paratype female, same data as holotype except for 1,100-1,200 m, June/July, 2016, E. van den Berghe coll. (ACMT).

Etymology: The new species is named for Bing Kirk, host and landowner at Cerro Jesus, where the holotype was collected.

\section{Enaphalodes monzoni, sp. nov.} (Figs. 17-23)

Diagnosis: Enaphalodes monzoni, sp. nov. is very similar to E. bingkirki, sp. nov., due to its short antennae, elytral maculations, and dense, erect, elytral setae. It is distinguished by the antennae just reaching the distal third of the elytra, the prothorax being somewhat wider but without a distinct lateral projection anterior to midpoint (Fig. 17), the pro- and mesosternal processes wider (Fig. 23), and the uniformly ochre pubescence dorsally. In E. bingkirki, the antennae reach the distal sixth of the elytra, the prothorax is relatively more slender and with a more pronounced projection laterally just anterior of midpoint (Fig. 9), the pro- and mesosternal processes are narrower (Fig. 24), and the dorsal pubescence is a mixture of ochre and yellowish-white setae. Like E. bingkirki, the dense, erect elytral pubescence in E. monzoni most easily distinguishes it from $E$. niveitectus.

Description: Holotype female: Integument mostly dark brown, almost black dorsally; mouthparts and legs dark reddish-brown with darker areas; antennae dark brown on basal segments, gradually reddish-brown toward distal segments. Pubescence and erect setae uniformly ochre.

Head: Frons centrally tumid close to clypeus, with deep fovea on each side close to clypeus; minutely, densely punctate, except nearly smooth tumid area, and narrow band along median groove; pubescence obscuring integument except glabrous tumid area and along median groove, interspersed with a few long, erect setae laterally. Area between antennal tubercles and upper eye lobes with moderately coarse, sparse punctures interspersed with dense, minute punctures; pubescence nearly obscuring integument, except glabrous area along median groove (widened, sub-diamond-shaped between upper eye lobes), interspersed with a few long, erect setae close to eyes. Remaining surface of vertex and area behind upper eye lobes, densely, confluently, shallowly punctate; pubescence forming two wide rounded lobes close to eyes, reaching to about middle of area behind upper eye lobes; wide area of vertex and area behind upper eye lobes close to prothorax glabrous. Area behind lower eye lobes striate-punctate; with band of pubescence close to eye, distinctly widened toward gena. Antennal tubercles flat, rounded at apex; densely, minutely punctate except smooth narrow area close to apex; pubescence nearly obscuring integument, interspersed with sparse, long, erect setae on frontal side, except glabrous smooth area. Genae finely, moderately sparsely punctate; with band of pubescence close to eye, with long, erect, sparse setae on remaining surface. Postclypeus minutely, sparsely punctate centrally, densely punctate at level of fovea on frons, smooth laterally; pubescent close to tumid area on frons, with short and long, moderately sparse setae on remaining surface except glabrous smooth area. Labrum coplanar with anteclypeus on basal $2 / 3$, inclined on distal third; sides of basal $2 / 3$ and entire distal third smooth; remaining surface of basal $2 / 3$ minutely, moderately abundantly punctate close to curvature, smooth basally; with short and long erect setae, denser centrally on inclined area. Gula smooth, glabrous. Submentum vermiculate, interspersed with fine punctures; with moderately sparse decumbent setae interspersed with long, erect setae. Distance between upper eye lobes 0.63 times length of scape; in frontal view, distance between lower eye lobes 0.92 times length of scape. Antennae 1.1 times elytral length, reaching base of distal third of elytra. Scape wide at base and not widened toward apex, flattened and slightly depressed dorsally on basal third, finely, densely punctate; pubescence not obscuring integument, interspersed with long, erect setae, distinctly more abundant ventrally. Antennomeres dorsoventrally flattened (less so at apex of III-VI); inner apex of antennomere III with acute spine, slightly narrower than distal width of antennomere; inner apex of antennomere IV with acute spine, with length equal to about 0.75 times distal width of antennomere; apex of antennomere $\mathrm{V}$ with acute spine, slightly longer than half of distal width of antennomere; antennomeres VI-X with short spine at inner apex, shorter, gradually shorter toward $\mathrm{X}$; antennomeres $\mathrm{V}-\mathrm{X}$ with short spine at outer apex, nearly indistinct on $\mathrm{V}-\mathrm{Vl}$; antennomeres with pubescence gradually shorter and denser toward distal segments; antennomeres III-VII with long, erect setae ventrally (sparser toward VII), and long, erect setae on 

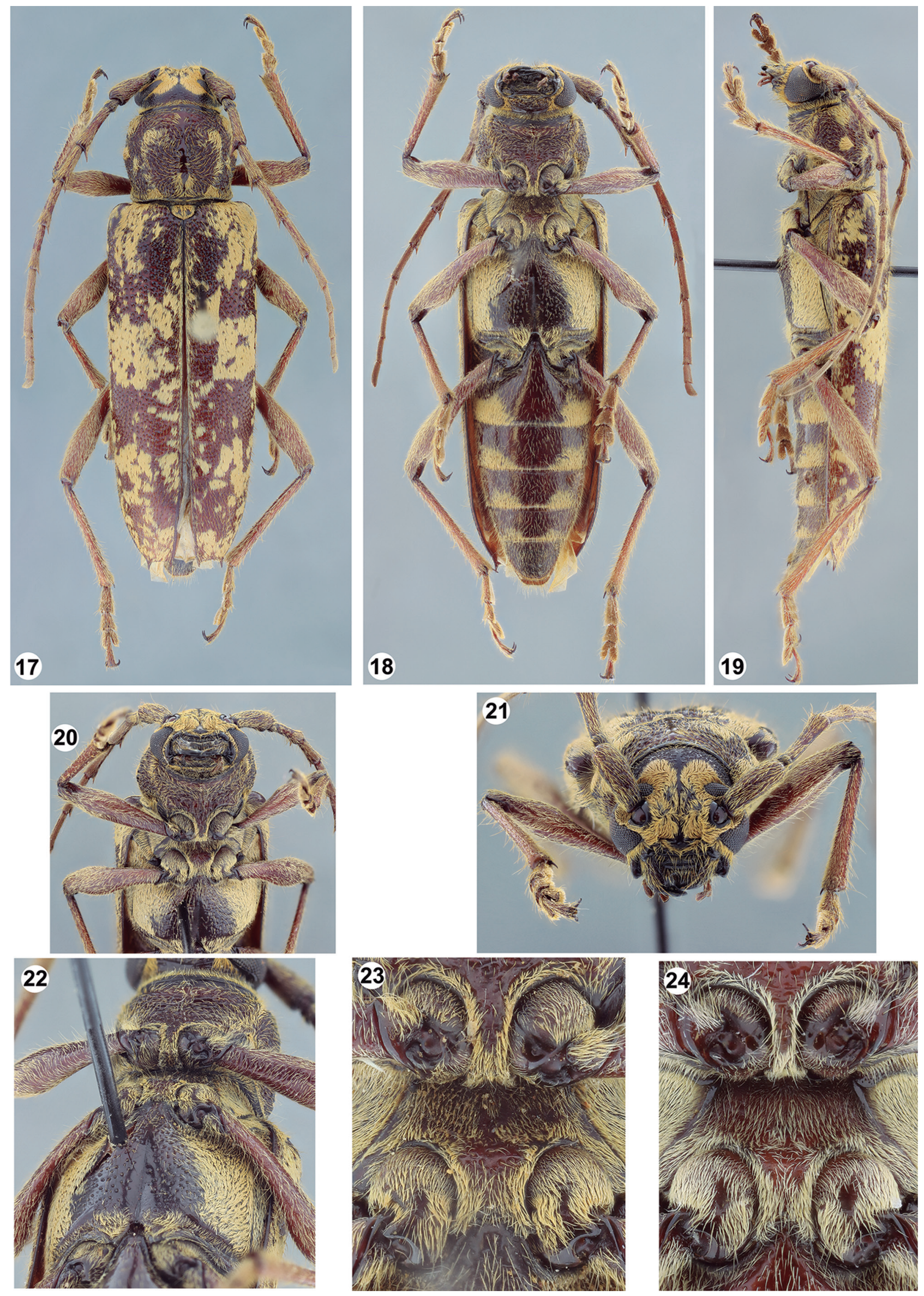

Figures 17-24. (17-23): Enaphalodes monzoni, sp. nov., holotype female: (17) Dorsal habitus; (18) Ventral habitus; (19) Lateral habitus; (20) Anteroventral view; (21) Head, frontal view; (22) Ventral side, oblique view; (23) Pro- and mesosternal processes. (24) E. bingkirki, sp. nov., holotype female, pro- and mesosternal processes. 
dorsal and ventral apex of III-X (gradually shorter toward $\mathrm{X}$ ). Antennal formula (ratio) based on length of antennomere III (excluding spine): scape $=1.04$; pedicel $=0.16$; $\mathrm{IV}=0.74 ; \mathrm{V}=0.90 ; \mathrm{VI}=0.87 ; \mathrm{VII}=0.82 ; \mathrm{VIII}=0.66$; $\mathrm{IX}=0.64 ; \mathrm{X}=0.53 ; \mathrm{XI}=0.64$.

Thorax: Prothorax 1.2 times wider than long, with distinct constriction near apex; sides rounded, with small, blunt tubercle at about middle. Pronotum with seven gibbosities: one elongate, placed centrally from near base to apex, distinctly narrowed between middle and distal third; two fused on each side of central gibbosity; one oblique, elongate, irregular, placed on sides of basal half, fused at apex with the latter ones. Pronotal surface coarsely, densely rugose-punctate, especially laterally, except smooth central gibbosity; pubescence dense on basal sides of central gibbosity, elongate band on outer side of fused gibbosities, strongly curved on top of posterolateral gibbosity (denser on its base and apex), irregular spot on distal area of oblique gibbosity, spot on lateral tubercle, and spot close to anterolateral angle; remaining surface with short, decumbent, sparse setae except glabrous central gibbosity. Sides of prothorax coarsely, densely rugose-punctate; with short, decumbent, sparse setae, denser close to prosternum, especially close to procoxal cavity. Prosternum coarsely, densely rugose-punctate (nearly vermiculate on basal $2 / 3$ ); with short, sparse, decumbent setae interspersed with long, erect setae, except narrow band with dense pubescence close to procoxal cavities. Prosternal process with narrow band of dense pubescence laterally on basal half, entirely pubescent on distal half. Mesosternum with pubescence partially obscuring integument. Mesepisternum, mesepimeron and metepisternum with pubescence obscuring integument. Mesosternal process strongly inclined toward mesosternum, with small tubercle on each side close to curvature. Metasternum coarsely, moderately abundantly punctate except smooth area close to central sulcus; sides with dense pubescence obscuring integument and wide triangular central area with sparse, erect setae. Scutellum with pubescence obscuring integument.

Elytra: Coarsely, densely punctate on basal third, gradually finer, sparser toward apex; with large, irregular maculae of dense pubescence; with long, erect, sparse setae throughout; apex truncate, bispinose (outer spine slightly longer).

Legs: Femora finely, densely punctate (punctures finer toward apex); pubescence not obscuring integument; apices of profemora with rounded lobe; apices of mesoand metafemora with subtriangular lobes.

Abdomen: Ventrites I-IV with large macula of pubescence on each side of distal half (about distal third on ventrite I); remaining surface with short, sparse, decumbent setae interspersed with long, erect setae (more abundant on $\mathrm{V}$ ); apex of ventrite $\mathrm{V}$ rounded, emarginate centrally.
Dimensions in mm: Total length, 27.15; prothorax: central length, 5.15; distal width, 4.35; basal width, 5.60; widest width, 6.15; humeral width, 8.10; elytral length, 20.00 .

Type material: Holotype female from GUATEMALA, Izabal: Sierra del Merendón (Finca Firmeza, $950 \mathrm{~m}$ ), 28.VIII-03.IX.2007, J. Monzón, F. Camposeco and R.E. Woodruff col. (FSCA).

Etymology: This species is named after José Monzón who collected the holotype and was host and collaborator to many entomological researchers in Guatemala.

\section{Enaphalodes cunninghami, sp. nov.}

(Figs. 25-31)

Diagnosis: Enaphalodes cunninghami, sp. nov. is similar to E. taeniatus, but differs especially by the elytral punctures (Fig. 31) being sparser, while in the latter they are distinctly denser (Fig. 32). Furthermore, the punctation of the metasternum (Fig. 26) is somewhat finer and sparser than on E. taeniatus (Fig. 52). It is also somewhat similar to E. senex, but differs particularly by the antennal tubercles being elevated (Figs. 27, 28), while in E. senex they are flattened (Figs. 35, 36, 55). It can be distinguished from $E$. niveitectus especially by the punctation on metasternum being sparser (denser in E. niveitectus), and antennomere IV being shorter and thicker (Fig. 25) (slender and long in E. niveitectus female, Fig. 48).

Description: Holotype female: Integument mostly black; mouthparts dark reddish-brown; antennae gradually becomingdark brown toward distal segments.

Head: Frons narrowly tumid close to clypeus, with deep fovea on each side close to clypeus; minutely, densely punctate interspersed with a few fine punctures, except smooth tumid area; with dense pale yellow pubescence laterally, especially on area of foveae, nearly glabrous on remaining surface. Area between antennal tubercles minutely, densely punctate interspersed with fine punctures (partially confluent on some areas), except smooth, narrow, carina-shaped area on each side of median groove; with very sparse pale yellow pubescence. Area from posterior side of antennal tubercles and upper eye lobes minutely, densely punctate centrally, sparser toward eyes; with densespot of pale yellowpubescence centrally, and dense band of same color close to eyes, gradually widened, yellower, forming two wide rounded lobes close to eyes, reaching to about middle of area behind upper eye lobes; area between dense pubescence nearly glabrous; with a few long, erect pale yellow setae close to eyes. Remaining surface of vertex and area behind upper eye lobes glabrous, moderately finely, densely, confluently punctate (punctures transverse) except nearly smooth central area between apices of rounded lobes of pubescence. Area behind lower eye lobes glabrous, smooth, shining close to eye, transversely striate toward prothorax. Antennal tubercles elevated, with blunt apex; minutely, abundantly punctate at base and 
close to apex, nearly smooth centrally and at apex; nearly smooth except for posterior area with dense pale yellow pubescence. Genae sparsely, shallowly, moderately, finely punctate toward eyes, smooth close to apex; with sparse pale yellow pubescence close to eye, nearly glabrous toward apex. Postclypeus finely, moderately sparsely punctate on wide central area, smooth laterally; with short, sparse yellow setae interspersed with long erect setae on
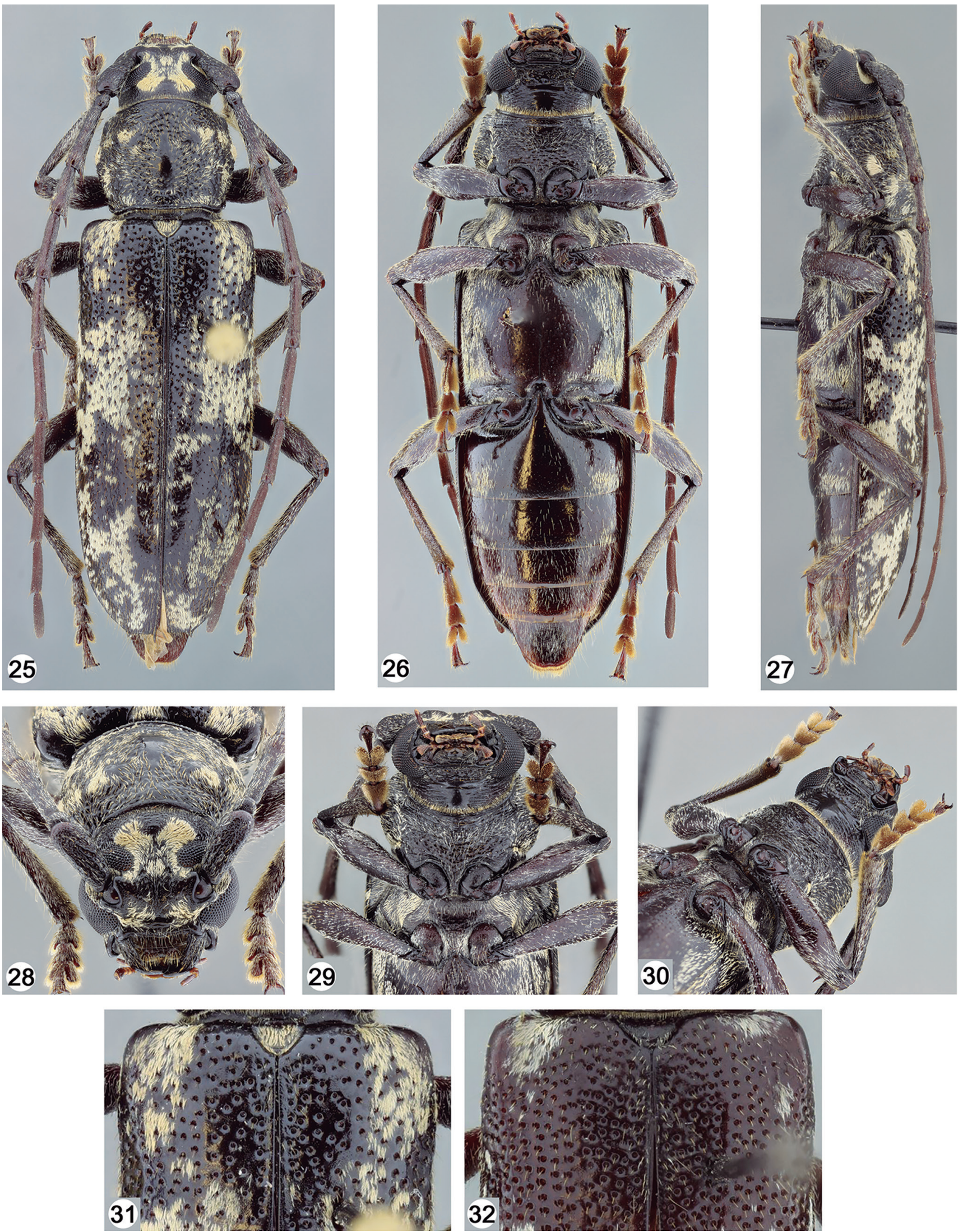

Figures 25-32. (25-31): Enaphalodes cunninghami, sp. nov., holotype female: (25) Dorsal habitus; (26) Ventral habitus; (27) Lateral habitus; (28) Head, frontal view; (29) Ventral head and thorax; (30) Ventral side, oblique lateral view; (31) Elytral sculpture. (32) E. taeniatus, female, elytral sculpture. 
punctate area, glabrous on smooth area. Labrum coplanar with anteclypeus on basal half, inclined on distal half; sides and base of basal half and sides of distal half smooth, remaining surface minutely, densely punctate; with long and short, moderately abundant yellow setae directed anteriorly on punctate area (less so centrally on basal half). Submentum rugose interspersed with fine punctures; with short and long, moderately dense, pale yellow setae. Distance between upper eye lobes 0.52 times length of scape; in frontal view, distance between lower eye lobes 0.95 times length of scape. Antennae 1.43 times elytral length, reaching elytral apex at middle of antennomere XI. Scape slightly widened toward apex, slightly longitudinally depressed dorsally (more distinctly on basal half), moderately coarsely rugose-punctate; with sparse, decumbent pale yellow setae, interspersed with long, erect pale yellow setae ventrally. Inner apex of antennomeres III-IV with acute spine, with length equal to 0.7 times distal width of antennomere, and outer angle rounded; inner apex of antennomere $V$ with acute spine, with length equal to 0.6 times distal width of antennomere, and outer angle forming right angle; inner apex of antennomere $\mathrm{VI}$ with acute spine, with length equal to 0.45 times distal width of antennomere, and outer angle with spicule; inner and outer apices of antennomeres VII-X with short, distinct spine; antennomeres with yellow pubescence, gradually shorter, denser yellowish-white toward distal segments; antennomeres III-VII with long, erect setae ventrally (sparser toward VII), and long, erect setae on dorsal and ventral apex of III-X (gradually shorter toward X). Antennal formula (ratio) based on length of antennomere III (excluding spine): scape $=0.84$; pedicel $=0.15 ; \mathrm{IV}=0.71 ; \mathrm{V}=0.92 ; \mathrm{VI}=1.01$; $\mathrm{VII}=1.01 ; \mathrm{VIII}=0.89 ; \mathrm{IX}=0.83 ; \mathrm{X}=0.74 ; \mathrm{XI}=0.74$.

Thorax: Prothorax 1.28 times wider than long, with distinct constriction near apex; sides rounded, with small but distinct blunt tubercle at about middle. Pronotum with five gibbosities: one elongate, placed medially from basal fifth to distal third (distinctly narrowed at its distal third); one irregular, slightly oblique, placed on each side of distal half; one, large, subcircular, slightly distinct, placed on each side of basal half. Pronotal surface coarsely rugose-punctate, except smooth central and posterolateral gibbosities; with sparse, decumbent pale yellow setae except some lateral spots with dense pubescence, and glabrous central and posterolateral gibbosities. Sides of prothorax rugose; with sparse, decumbent pale yellow setae except spot with dense pubescence on base of lateral tubercle and denser pubescence near procoxal cavity. Prosternum rugose-punctate on basal third, striate-punctate on central third, moderately sparsely punctate on distal third; with sparse, decumbent pale yellow setae interspersed with long, erect setae. Prosternal process rugose-punctate on basal area, with narrow central carinae at about middle, slightly centrally depressed toward apex; basal half with sparse, pale yellow pubescence interspersed with long, erect setae, and distal half with dense, short pubescence not obscuring integument. Mesosternum with pale yellow pubescence distinctly exposing integument. Mesepisternum, mesepimeron and metepisternum with dense pale yellow pubescence nearly obscuring integument. Metasternum minutely, sparsely punctate laterally, gradually finer punctate toward central sulcus; with dense pale yellow pubescence interspersed with long, erect setae laterally, with long, erect sparse setae on wide central area except glabrous area near central sulcus. Scutellum with dense pale yellow pubescence.

Elytra: Coarsely, moderately abundantly punctate on basal half, gradually finer, sparser toward apex; with three important groups of dense, irregular yellowish-white pubescence, one on each side of basal sixth (more yellow), one occupying at about central third, and another occupying distal third; area between dense pubescence with short, erect, sparse yellowish setae; apex truncate, bispinose (sutural spine distinctly longer than outer one).

Legs: Femora minutely, moderately sparsely punctate interspersed with fine punctures; with yellow setae not obscuring integument; apices of profemora with rounded lobes; apices of meso- and metafemora with subtriangular lobes.

Abdomen: Ventrites minutely, sparsely punctate, gradually denser toward V; with short, decumbent, sparse pale yellow setae, gradually more abundant toward $V$ and toward sides; with spot of dense, yellowish-white pubescence on sides of I and II (larger, more distinct on I); apex of ventrite $\mathrm{V}$ rounded, centrally emarginate.

Dimensions in mm: Total length, 26.20; prothorax: central length, 4.72; distal width, 3.69; basal width, 5.00; widest width, 6.12; humeral width, 7.29; elytral length, 18.10.

Type material: Holotype female from MEXICO, Baja California Sur: Hwy 1 (San Antonio town), 14.VIII.2007, Cunningham col. (CNIN).

Etymology: This species is named after Richard Cunningham, an avid Coleopterist who collected the holotype.

\section{Enaphalodes senex (Bates, 1884), revalidated} (Figs. 33-47)

Hypermallus senex Bates, 1884: 248; Schaeffer, 1908: 327, 333; Aurivillius, 1912: 84 (syn.); Blackwelder, 1946: 465

Redescription: Male: Integument mostly dark brown; mouthparts dark reddish-brown; parts of epipleura reddish-brown; apex of abdominal ventrites I-IV light reddish-brown. Pubescence of elytra and head primarily white.

Head: Frons centrally tumid close to clypeus, with deep fovea on each side close to clypeus; with white pubescence obscuring integument except nearly glabrous tumid area. Vertex with white pubescence obscuring integument between antennal tubercles and upper eye lobes 
(except nearly glabrous, irregular small area on each side between antennal tubercles and upper eye lobes), then forming two wide rounded lobes close to eyes reaching to about middle of area behind upper eye lobes; remaining surface of vertex and area behind upper eye lobes moderately finely, densely, confluently punctate; with short, sparse, decumbent golden setae; with long, erect, sparse golden setae near eyes. Area behind lower eye lobes smooth and glabrous close to eye, somewhat striate-punctate, nearly glabrous toward prothoracic
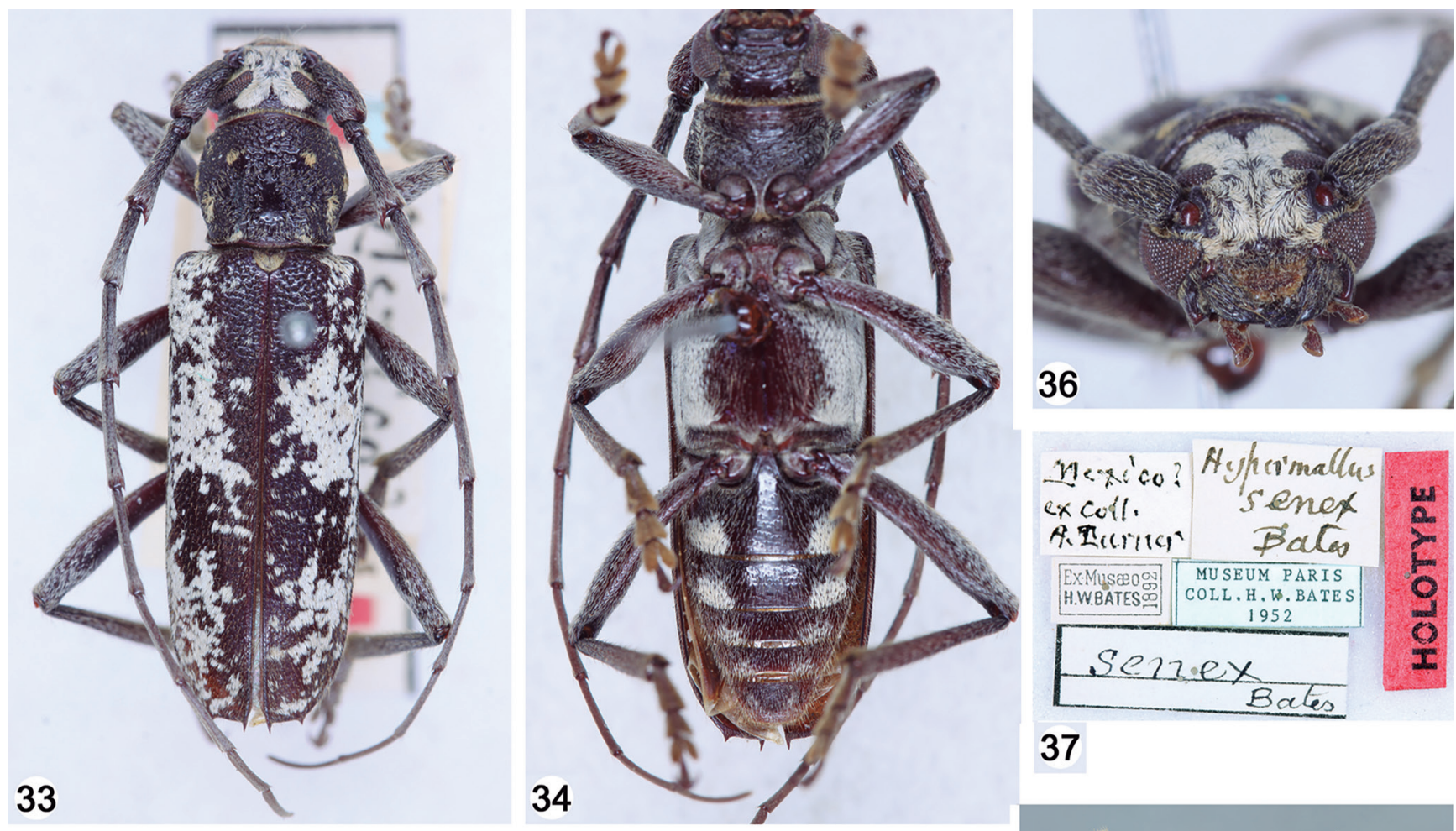

\section{7}
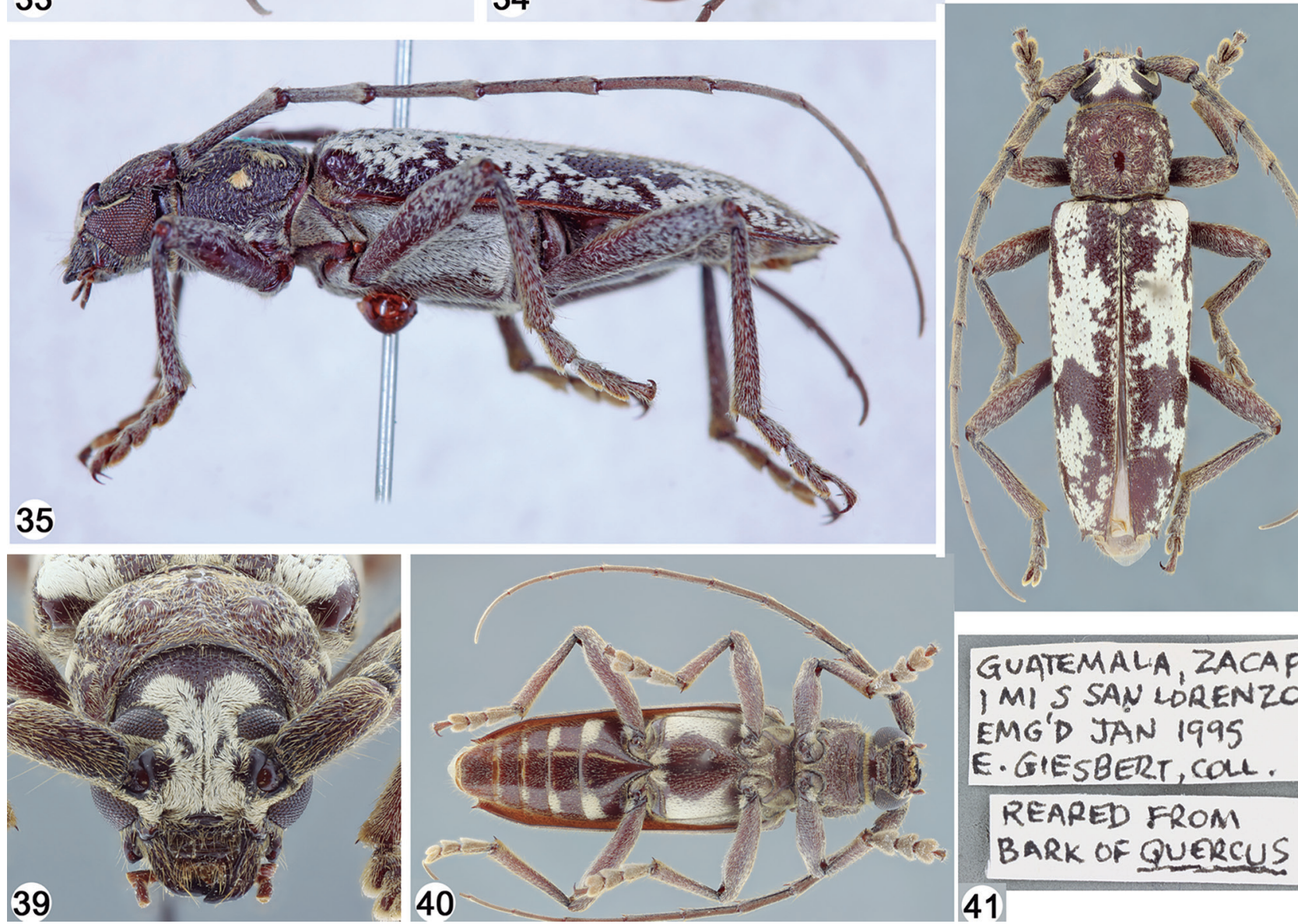

GUATEMALA, ZACAPA IMI S SAN LORENZO EMG'D JAN 1995 E. GIESBERT, COL.

REARED FROM BARK OF QUERCUS 41

Figures 33-41. Enaphalodes senex (Bates). (33-37): Hypermallus senex Bates, holotype male: (33) Dorsal habitus; (34) Ventral habitus; (35) Lateral habitus; (36) Head, frontal view; (37) Labels. (38-41): Male from Guatemala: (38) Dorsal habitus; (39) Head, frontal view; (40) Ventral habitus; (41) Labels. 
margin, but with narrow transverse band with yellow setae starting at about distal third close to smooth region, becoming wider, denser and close to eye toward ventral side of lobe. Antennal tubercles flat; with pale yellow pubescence obscuring integument on basal area, sparser on wide dorsal area, glabrous close to apex; area with sparse pubescence finely, abundantly punctate. Genae coarsely, smoothly punctate on central area, nearly smooth close to eyes and smooth toward apex; with decumbent, sparse, yellow setae, denser close to eyes and sparser
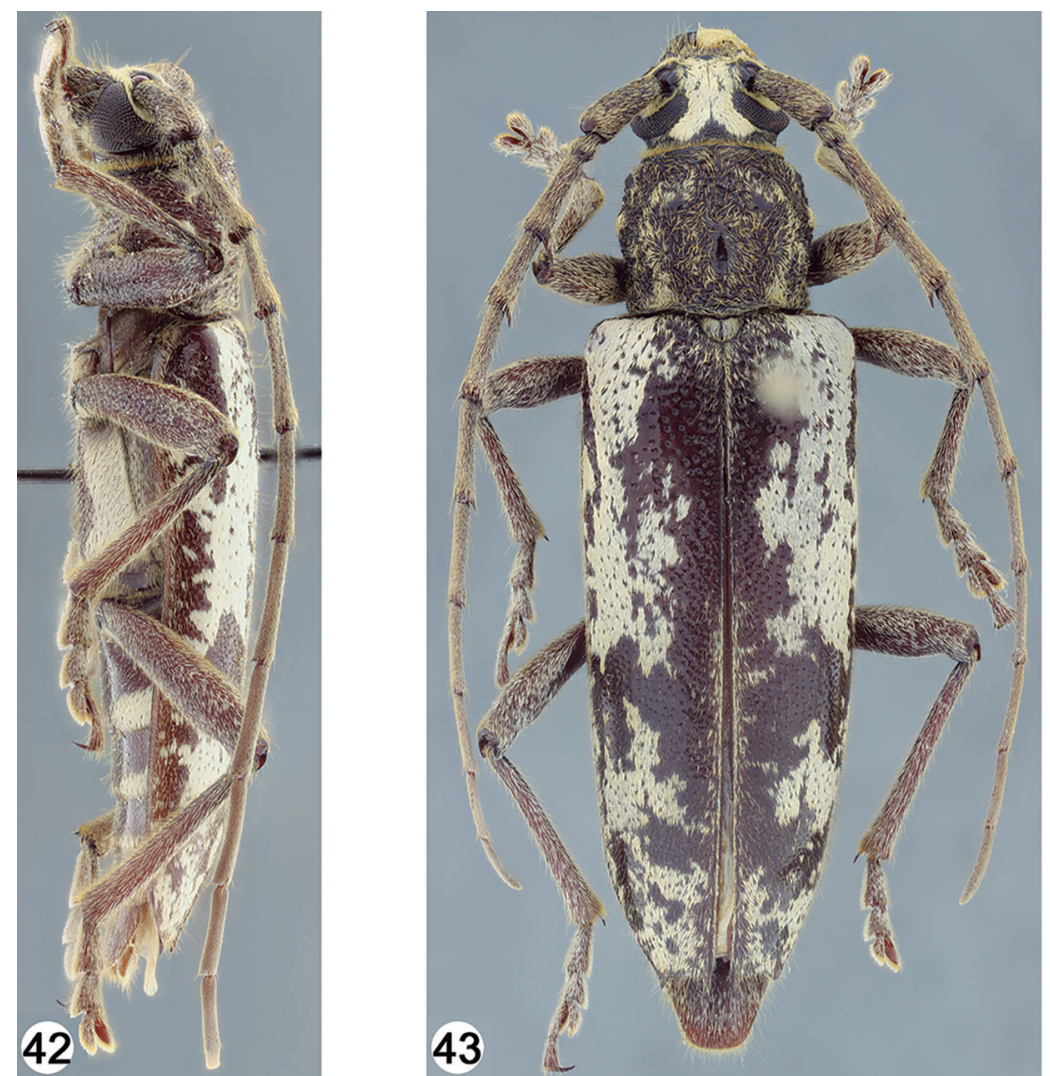
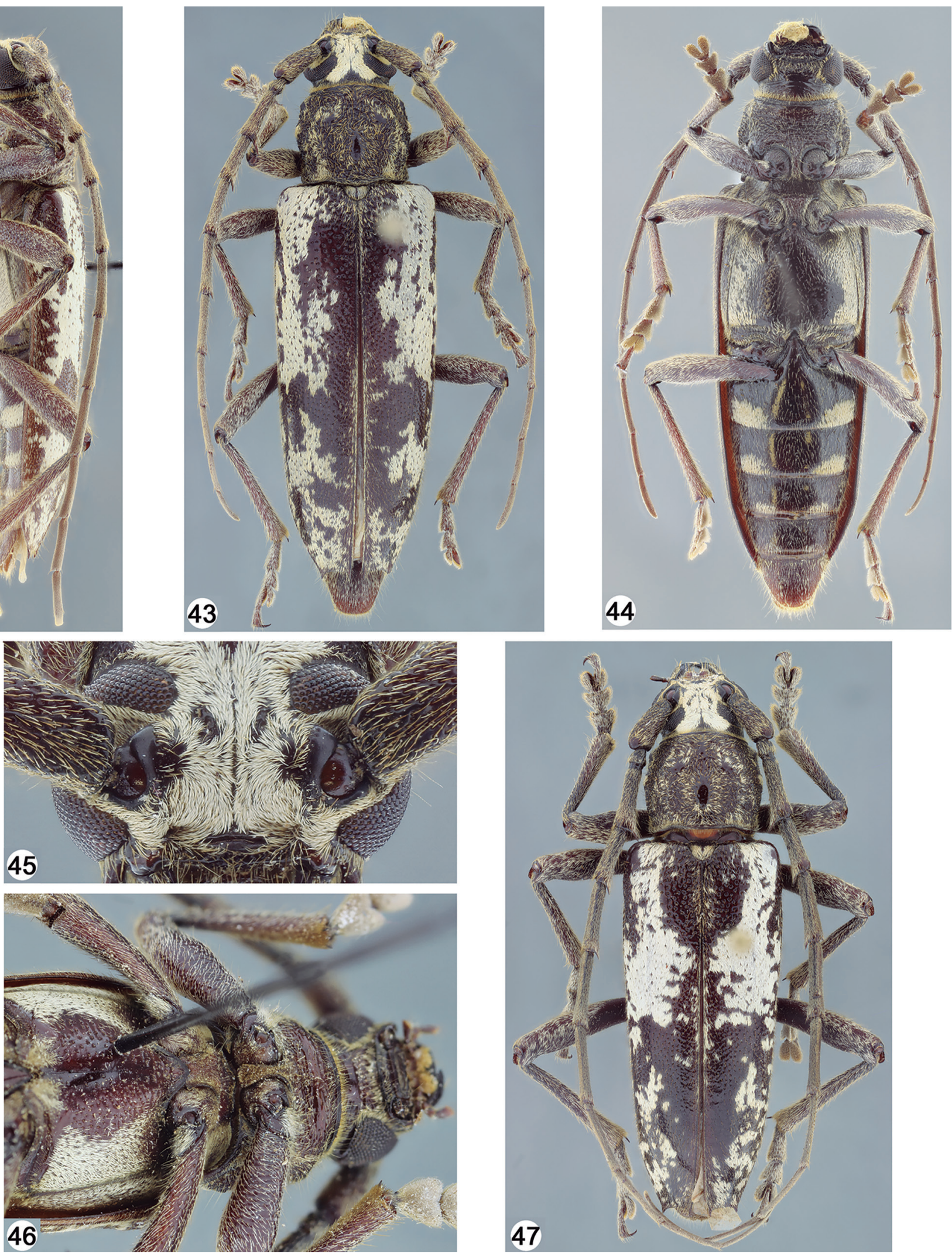

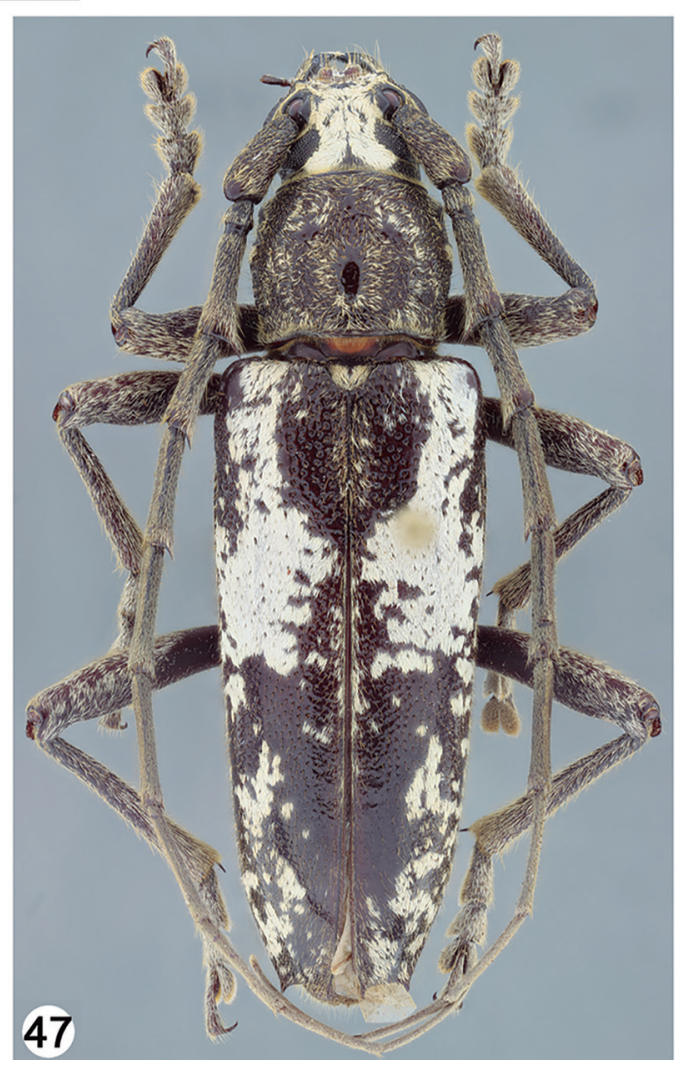

47

Figures 42-47. Enaphalodes senex (Bates): (42) Male from Guatemala, lateral habitus; (43) Female from Guatemala, dorsal habitus; (44) Female from Guatemala, ventral habitus; (45) Male from Guatemala, antennal tubercles; (46) Male from Guatemala, prosternal process, lateral view; (47) Male from Nicaragua, dorsal habitus. 
close to apex, interspersed with long, erect, sparse, yellow setae. Postclypeus carina-shaped on each side of central area (starting at level of fovea of frons); with short and long, erect, sparse yellow setae except glabrous sides. Labrum coplanar with anteclypeus on basal half, inclined on distal half (centrally depressed on distal half); with
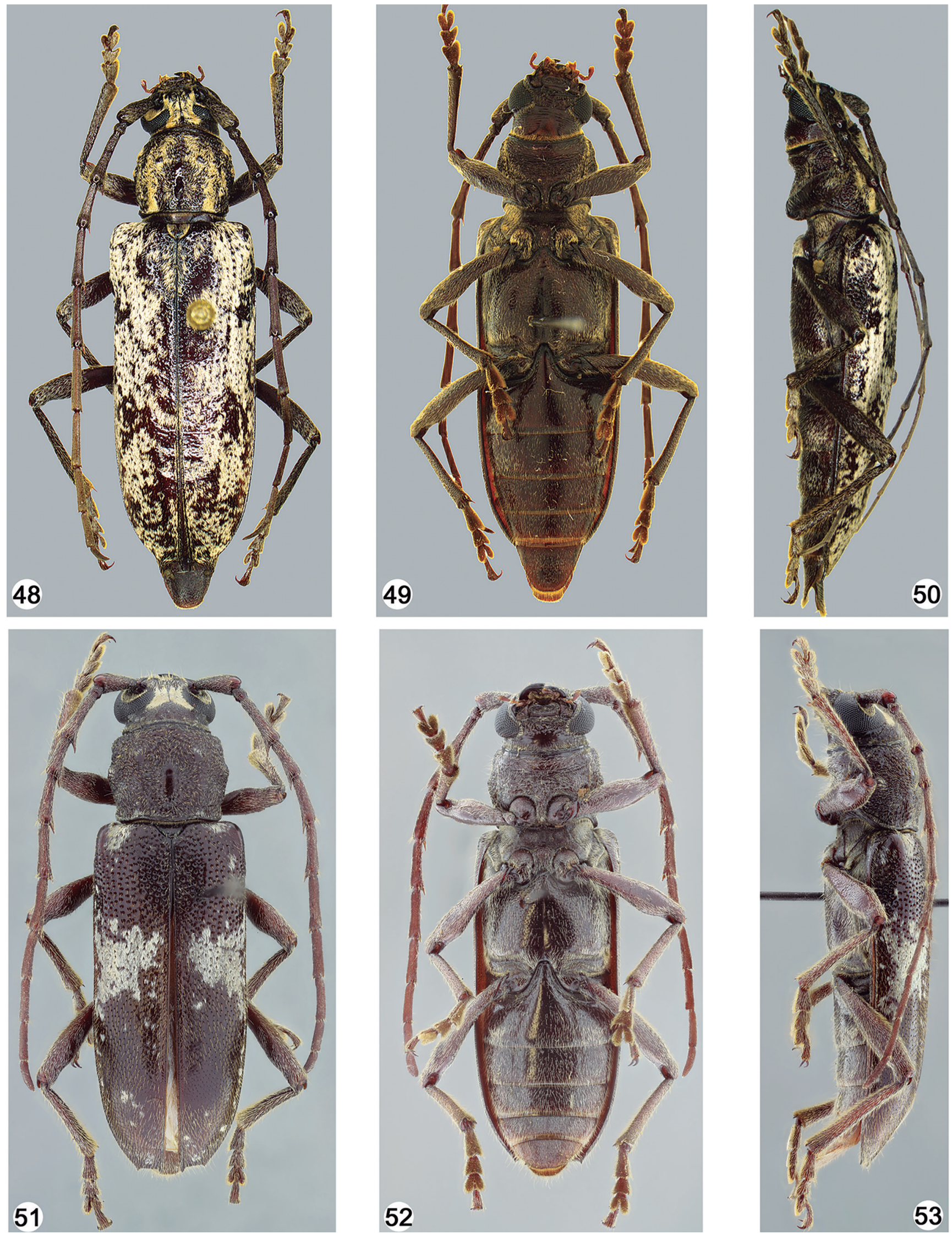

Figures 48-53. (48-50): Enaphalodes niveitectus (Schaeffer), female: (48) Dorsal habitus; (49) Ventral habitus; (50) Lateral habitus. (51-53): E. taeniatus (LeConte), female: (51) Dorsal habitus; (52) Ventral habitus; (53) Lateral habitus. 
fine, sparse punctures on basal half close to inclined area; glabrous on center of basal half, with long, erect, sparse yellowish-brown setae on remaining surface (denser on inclined area, especially laterally). Gula smooth, glabrous. Submentum coarsely, shallowly, confluently punctate; with short yellowish-brown pubescence not obscuring integument, interspersed with long, erect, moderately sparse yellowish-brown setae. Distance between upper eye lobes 0.5 times length of scape; in frontal view, distance between lower eye lobes 0.9 times length of scape. Antennae 1.75 times elytral length, reaching elytral apex near apex of antennomere IX. Scape wide at base and not widened toward apex, flattened at basal third, irregularly depressed dorsally on basal third, somewhat vermiculate dorsally on basal 2/3; moderately finely, densely punctate; with short, decumbent yellow setae not obscuring integument, interspersed with long, erect, sparse yellow setae (more abundant ventrally). Antennomeres dorsoventrally flattened (less so at apex of III-VI); inner apex of antennomere III with acute spine, slightly shorter than distal width of antennomere; inner apex of antennomere IV with acute spine, with about half of distal width of antennomere; antennomeres $\mathrm{V}$-X with short spine at inner and outer apices, shorter at outer apex of V-VII; antennomeres with yellow pubescence, gradually shorter and denser toward distal antennomeres; antennomeres III-VI with long, erect yellowish setae ventrally, gradually sparser toward VI; antennomeres III-X with, long, erect, sparse yellow setae dorsally close to apex. Antennal formula (ratio) based on length of antennomere III (excluding spine): scape $=1.03$; pedicel $=0.24 ; \mathrm{IV}=0.91 ; \mathrm{V}=1.07$; $\mathrm{VI}=1.12 ; \mathrm{VII}=1.15 ; \mathrm{VIII}=1.10 ; \mathrm{IX}=1.05 ; \mathrm{X}=0.95 ; \mathrm{XI}=1.22$.

Thorax: Prothorax wider than long, with distinct constriction near apex; sides slightly rounded (sometimes with slightly indicated tubercle on distal half close to middle). Pronotum with seven gibbosities: one elongate, slightly oblique, placed on each side of basal half (from near base to middle); one subcircular, placed on each side of distal half; one longitudinal, placed medially from basal quarter to apex (distinctly narrowed between anterolateral gibbosities); one oblique, placed near lateral curvature, from basal quarter to anterolateral gibbosities. Pronotal surface coarsely, shallowly, confluently punctate except on smooth central gibbosity, and central area between central gibbosity and basolateral gibbosities with fine punctures; with short, decumbent yellow setae not obscuring integument, denser, more yellowish-white laterally close to gibbosities, and forming small, irregular spots laterally on distal half and at base of central callus; with long erect, yellow, sparse setae laterally. Sides of prothorax coarsely rugose-punctate; with short, sparse yellow setae (denser close to procoxal cavity and close to prosternum) interspersed with long, erect, sparse yellow setae. Prosternum transversely, widely sulcate centrally; coarsely, moderately densely punctate on basal $2 / 3$, transversely striate-punctate on distal third; with short, decumbent, sparse yellow setae interspersed with long, erect yellow setae. Mesosternum with short yellowish pubescence, slightly distinct depending on angle of light, slightly denser laterally. Mesepisternum and mesepimeron with yellow pubescence partially obscuring integument. Mesosternal process strongly inclined toward mesosternum, with one small tubercle on each side close to inclined area. Metepisternum with yellowish-white pubescence obscuring integument, slightly yellower basally. Mesosternal process inclined toward mesosternum, with one small tubercle on each side of curvature. Metasternum coarsely, moderately abundantly punctate, gradually sparser toward central sulcus; sides with yellowish-white pubescence obscuring integument (whiter than on metepisternum), not reaching mesocoxal cavity, and distally on each side of central sulcus (yellower than laterally); remaining surface with long, moderately sparse, suberect yellow setae. Scutellum with yellowish-white pubescence obscuring integument.

Elytra: Densely punctate throughout, punctures coarser on basal half, gradually finer toward apex; with two groups of important maculae of dense white pubescence with irregular margins (Figs. 33, 43): one elongate, from humerus to middle, nearly continuous, with two projections toward epipleura (one at about its middle, another at its apex); another fragmented, on sides of distal half, nearly absent close to middle of elytra; with long, erect, sparse yellow setae throughout (more abundant toward apex); apex truncate, bispinose (outer spine broader than sutural one).

Legs: Femora coarsely, moderately densely punctate, striate-punctate on basal half of profemora; with yellowish-white pubescence partially obscuring integument, interspersed with long, erect yellow setae ventrally; apices with rounded lobes.
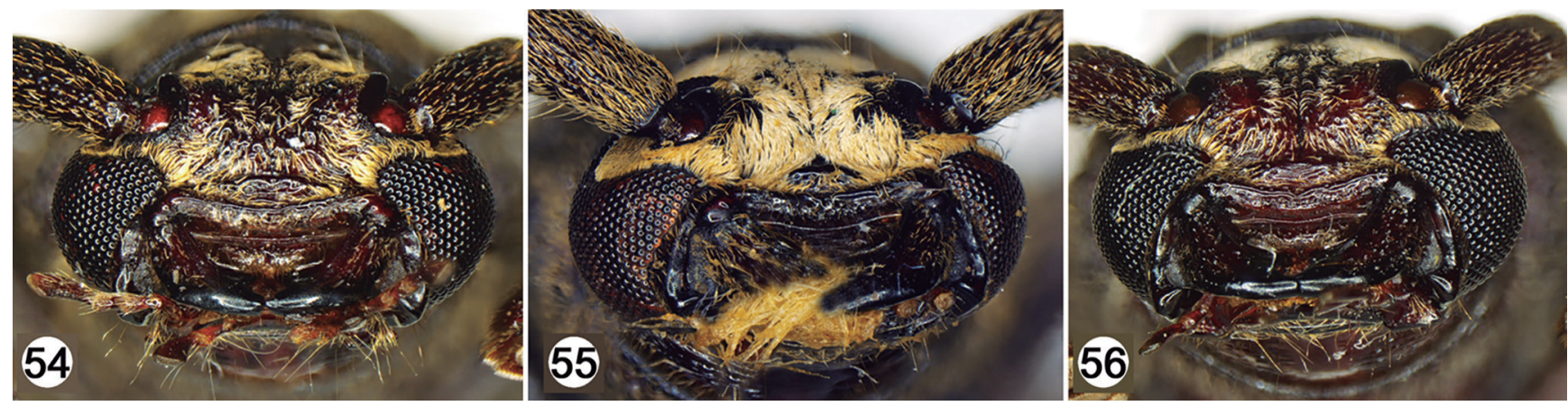

Figures 54-56. Antennal tubercles: (54) E. niveitectus (Schaeffer), female; (55) E. senex Bates, female; (56) E. taeniatus (LeConte), female. 
Abdomen: Ventrites with short, sparse yellow-ochraceous pubescence, sparser centrally, and distinctly denser yellowish-white pubescence on distal area of sides of ventrites I-IV (gradually narrower toward IV); apex of ventrite $V$ truncate, slightly emarginate centrally.

Female: Antennae 1.35 times elytral length, reaching elytral apex at distal quarter of antennomere XI; scape narrower than in male. Apex of abdominal ventrite $\mathrm{V}$ rounded.

Variation: Spots of pubescence on pronotum ranging from pale yellow to ochre; pubescence on sides of pronotum moderate to dense, partially obscuring integument, forming spots or not, except on tubercle-shaped sides; outer spine of elytral apex of varying length: shorter than or subequal to sutural spine.

Dimensions in $\mathbf{m m}$ (male/female): Total length, 23.05-25.70/29.25; prothorax: central length, 4.40-4.70/4.80; distal width, 3.65-4.00/4.10; basal width, 4.65-4.95/5.35; widest width, 5.15-5.80/5.85; humeral width, 6.40-6.95/7.60; elytral length, 16.15-18.00/19.40.

Material examined: GUATEMALA (new country record), Zacapa: $1 \mathrm{mi} S$ San Lorenzo (reared from bark of Quercus sp.), 2 males, I.1995, E. Giesbert col. (FSCA); vic. San Lorenzo (5,000'), 1 female, 10-15.VI.1991, E. Giesbert col. (FSCA). NICARAGUA (new country record), Madriz: Tepesomoto-Pataste Natural Reserve $(1,350 \mathrm{~m}), 1$ male, 20.IV.2006, E. van den Berghe col. (DJHC).

Remarks: Bates (1884) described Hypermallus senex from a single specimen originating from Mexico, which he speculated was from the northern part of the country. Schaeffer (1908) reported: "The description of this species agrees so closely with the male of Romaleum taeniatum Lec. that I suspect the identity of the two." This suggestion was wrongly interpreted as a formal synonym by Aurivillius (1912), and was not questioned by any author who wrote subsequently on E. taeniatus. The only exception was found in Blackwelder (1946) who listed E. senex as a valid species, but did not list E. taeniatus. Thus, his intentions were unclear.

Enaphalodes senex differs from E. taeniatus as follows: the elytral punctation is sparser (Figs. 33, 38, 43, 47), the antennal tubercles are not elevated (Figs. 36, 55), and the elytral maculae are formed from white pubescence covering larger areas (Figs. 33, 38, 43, 47). In E. taeniatus, the elytral punctation is denser (Fig. 32), the antennal tubercles are elevated (Fig. 56), and the elytral maculae are comprised of white pubescence covering smaller areas (Fig. 51). It differs from $E$. niveitectus by having the antennal tubercles flat and rounded at the apex (Figs. 36, 55), the pubescence on the metepisternum and sides of metasternum distinctly denser (Figs. 40, 44, 46), and the ventrites having dense bands of white pubescence. In E. niveitectus, the antennal tubercles are elevated and acute at the apex (Fig. 54), the pubescence on the metepisternum and sides of the metasternum is distinctly sparser (Fig. 49), and the ventrites lack bands with white pubescence (Fig. 49). Enaphalodes senex differs most notably from E. bingkirki and E. monzoni in having antennae at least as long as the body in females. In females of E. bingkirki (Figs. 9, 11) and E. monzoni (Figs. 17, 19), the antennae are much shorter than the elytra.

Enaphalodes senex was originally described from Mexico. Additional specimens examined from Guatemala and Nicaragua expand the known distribution and represent new country records. Our concept of this species as distinct from Enaphalodes taeniatus removes the United States from the known distribution.

\section{Key to species of Enaphalodes (updated from Lingafelter \& Chemsak, 2002)}

1. Elytra with pubescence dense and conspicuous, either erect or appressed or in combination

- Elytra with very sparse, inconspicuous pubescence; U.S.A. (Arizona, California), Mexico (Sonora) .................... E. seminitidus (Horn, 1885)

2(1). Elytra with one to three well-defined areas of dense, appressed pubescence...

Elytra with pubescence otherwise: either uniform, without patches of dense, appressed pubescence, or with numerous interconnecting, poorly defined appressed patches, giving a mottled appearance ...6 6

3(2). Mesosternal process with large central tubercle (Fig. 5); meso- and metafemoral apices spiniform (Fig. 4).....

Mesosternal process with small tubercle on each side close to curvature (Fig. 8); meso- and metafemoral apices with rounded or triangular lobes (Fig. 7)

4(3). Elytral pubescence scattered, mostly pale yellow-ochre, forming three distinct groups of spots (Fig. 1); Costa Rica.

E. antonkozlovi, sp. nov.

- Elytral pubescence compact, white, forming two groups of maculae; Panama, Colombia .................................... boyacanus Martins, 2005

5(3). Elytra without dense patch of white pubescence on distal area (Fig. 51); U.S.A (Texas), Mexico (Tamaulipas).

E. taeniatus (LeConte, 1854)

- Elytra with patch of white pubescence at apex (Fig. 6); Mexico (Chiapas, Oaxaca), Guatemala, Honduras, Belize, Nicaragua, Costa Rica E. coronatus (White, 1853)

6(2). Elytra not appearing mottled; without patches of appressed pubescence; erect, suberect, and appressed pubescence uniform in density and distribution..

- Elytra appearing mottled; with patches of appressed pubescence; erect, suberect, or appressed pubescence not uniform in density and distribution

7(6). Large species, with pubescence inconspicuous and not heavily obscuring elytral surface; ventral pubescence mostly translucent with slight golden sheen; last ventral sternite of females with a deep notch at apex; U.S.A. (Georgia, Missouri, California, Arizona, Texas, Idaho, Florida, Minnesota, New Jersey, Mississippi, Alabama), Mexico (Sonora, Tamaulipas).............. E. hispicornis (Linnaeus, 1767) Moderate to large species with conspicuous uniform appressed fulvous pubescence that densely covers elytral surface; ventral pubescence mostly white and not translucent, distinctly different color from dorsal pubescence; last ventral sternite of females with a very 
shallow notch at apex; U.S.A. (Florida)

E. archboldi Lingafelter \& Chemsak, 2002

8(6). Sides of pronotum at middle nearly as wide as base of elytra in males; elytra light to dark brown with appressed pubescence extensive not contrasting as intensely with elytral ground color (appearing diffusely mottled) ..... 9

- $\quad$ Pronotum with slight widening anterior to middle, but much narrower at widest point than base of elytra; elytra dark brown with appressed pubescence distinctly mottled.

... 11

9(8). Elytra with fulvous appressed pubescence and reddish or light brown ground color; without erect setae (except a few along suture and apical third); last abdominal sternite of females with very shallow notch at apex; Canada (Quebec, Ontario), U.S.A. (Georgia, Philadelphia, Texas, New York, South Carolina, Maine, Florida, Minnesota, lowa, Ohio, Kentucky, Pennsylvania, Arizona, Mississippi, Massachusetts, Arkansas, Missouri, Alabama, Rhode Island, Maryland, Delaware, District of Columbia)

E. rufulus (Haldeman, 1847)

- Elytra with white or off-white appressed pubescence and light to dark brown ground color (rarely reddish-brown); longer erect to suberect setae present; last abdominal sternite of females with deep or shallow notch at apex... .... 10

10(9). Pubescence of metasternum primarily translucent; last abdominal sternite of female deeply notched at apex; elytra with diffuse patches of off-white pubescence; Canada (Quebec, Ontario), U.S.A. (New York, Pennsylvania, Maryland, North Carolina, Massachusetts, Texas, District of Columbia, Georgia, Florida, Arizona, Mississippi, Alabama, Arkansas, Colorado, Connecticut, lowa, Illinois, Indiana, Kansas, Louisiana, Michigan, Missouri, New Jersey, Ohio, Oklahoma, Rhode Island, South Carolina, Tennessee, Wisconsin), Mexico (Veracruz, Tamaulipas), Honduras. E. atomarius (Drury, 1773)

- Pubescence of metasternum primarily white and not translucent; last abdominal sternite of female with very shallow notch at apex; elytra with diffuse patches of white or off-white pubescence; U.S.A. (Pennsylvania, Arizona, New York, Illinois, North Dakota, Ohio, Kentucky, New Jersey, Virginia, Mississippi, Nebraska), Mexico (Sonora) ...................................... E. cortiphagus (Craighead, 1923)

11(8). Apex of antennal tubercles elevated (Figs. 28, 54)........................ 12

- Apex of antennal tubercles flattened (Fig. 55) ............................... 13

12(11). Prothorax wide, distinctly rounded laterally (Figs. 25, 28); antennomere IV short, thick, shorter than median pronotal impunctate region (Fig. 25); Mexico (Baja California Sur).

E. cunninghami, sp. nov.

- Prothorax moderately narrow, not distinctly rounded laterally (Fig. 48); antennomere IV elongate, narrow, longer than median pronotal impunctate region (Fig. 48); Mexico (Tamaulipas) E. niveitectus (Schaeffer, 1905)

13(11). Antennae in female reaching elytral apex (Fig. 43); pubescence of head and elytra primarily white; Mexico, Guatemala

E. senex (Bates, 1884)

- Antennae in female not reaching elytral apex; pubescence of head and pronotum ochre or yellowish-white ... 14

14(13). Antennae reaching at about base of distal third of elytra (Fig. 17); pro- and mesosternal processes wide (Fig. 23); uniformly ochre pubescence; Guatemala

E. monzoni, sp. nov. Antennae distinctly surpassing base of distal third of elytra (Fig. 9); pro- and mesosternal processes narrow (Fig. 24); pubescence a mixture of ochre and yellowish-white; Nicaragua ....E. bingkirki, sp. nov.

\section{ACKNOWLEDGMENTS}

We thank James E. Wappes (ACMT), Daniel J. Heffern (DJHC), Peter Oboyski (EMEC), Frederick W. Skillman, Jr. (FWSC), Paul Skelley (FSCA), and Max Barclay (BMNH), for providing specimens and photographs from collections under their care. We thank Anton O. Kozlov, José Monzón, and Richard Cunningham for their deposition of holotypes in this work. We thank and acknowledge Roman Gortovannyi (Zhukovsky, Russia) for assistance and friendship to Anton Kozlov that resulted in the discovery of one of the holotypes described in this work. We thank Bing Kirk for allowing access to his property in Cerro Jesus where many great specimens of Enaphalodes and other Cerambycidae have been collected. Thanks to Norman Woodley and two anonymous reviewers for reviewing this manuscript and providing suggestions for improvement.

\section{REFERENCES}

Aurivillius, C. 1912. Coleopterorum Catalogus, pars 39, Cerambycidae: Cerambycinae. Berlin,W. Junk. 574p.

Bates, H.W. 1884. Biologia Centrali-Americana, Insecta, Coleoptera, suppl. to Longicornia. London. v. 5, p. 225-248.

Blackwelder, R.E. 1946. Checklist of the coleopterous insects of Mexico, Central America, the West Indies and South America. Part 4. Bulletin of the United States National Museum, 185: 551-763.

Bousquet, Y. \& Bouchard, P. 2013. The genera in the second catalogue (1833-1836) of Dejean's Coleoptera collection. Zookeys, 282: 1-219.

Dejean, P.F.M.A. 1833-1836. Catalogue des coléoptères de la collection de M. le comte Dejean. Deuxième Édition. Paris, Méquignon-Marvis Père et Fils. 443p. (Livraison 1 \& 2, p. 1-176: 1833; Livraison 3, p. 177-256: 1834; Livraison 4, p. 257-360: 1835; Livraison 5, p. 361-443: 1836).

Haldeman, S.S. 1847. Descriptions of several new species and one new genus ofinsects. Proceedings of the Academy of Natural Sciences of Philadelphia, 3: 149-151.

International Commission on Zoological Nomenclature - ICZN. 1999. International Code of Zoological Nomenclature, 4.ed. London, The International Trust for Zoological Nomenclature, c/o The Natural History Museum. 306p.

Lingafelter, S.W. \& Chemsak, J.A. 2002. A new species of Enaphalodes Haldeman from Florida (Coleoptera: Cerambycidae) with review of genus, synonymy, and key to species. The Coleopterists Bulletin, 56(4): 569-581.

Linsley, E.G. 1963. The Cerambycidae of North America. Part IV. Taxonomy and classification of the subfamily Cerambycionae, tribes Elaphidionini through Rhinotragini. University of California Publications in Entomology, 21: 1-165.

Martins, U.R. 2005. Tribo Elaphidionini. In: Martins, U.R. (Org.). Cerambycidae Sul-americanos (Coleoptera) Taxonomia. Curitiba, Sociedade Brasileira de Entomologia. v. 7.

Monné, M.A. 2005. Catalogue of the Cerambycidae (Coleoptera) of the Neotropical Region. Part I. Subfamily Cerambycinae. Zootaxa, 946: 1-400.

Schaeffer, C.F.A. 1908. List of the longicorn Coleoptera collected on the Museum expeditions to Brownsville, Texas and the Huachuca Mts., Arizona, with descriptions of new genera and species and notes on known species. Science Bulletin of the Museum of the Brooklyn Institute of Arts and Sciences, 1(12): 325-352. 